\title{
Effects of GLP-1 on counter-regulatory responses during hypoglycemia after GBP surgery
}

\author{
Kristina E Almby ${ }^{1, *}$, Niclas Abrahamsson ${ }^{1, *}$, Martin H Lundqvist', Ulf Hammar ${ }^{1}$, Ketan Thombare ${ }^{1}$, \\ Amalia Panagiotou' ${ }^{2}$, A Anders Karlsson' ${ }^{1}$, Magnus Sundbom ${ }^{3}$, Urban Wiklund ${ }^{4}$ and Jan W Eriksson ${ }^{1}$ \\ ${ }^{1}$ Department of Medical Sciences, Uppsala University, ${ }^{2}$ Department of Internal Medicine, Uppsala University \\ Hospital, ${ }^{3}$ Department of Surgical Sciences, Uppsala University, Uppsala, Sweden, and ${ }^{4}$ Department of Radiation \\ Sciences, Biomedical Engineering, Umeå University, Umeå, Sweden \\ Correspondence \\ should be addressed \\ *(K E Almby and N Abrahamsson contributed equally to this work) \\ to J W Eriksson \\ Email \\ jan.eriksson@medsci.uu.se
}

\begin{abstract}
Objectives: The aim of the study was to explore the role of GLP-1 receptor activation on the counter-regulation and symptoms of hypoglycemia in subjects who have undergone gastric bypass surgery (GBP).

Design: Experimental hyperinsulinemic-hypoglycemic clamp study.

Methods: Twelve post-GBP subjects participated in a randomized cross-over study with two hyperinsulinemic, hypoglycemic clamps (glucose nadir $2.7 \mathrm{mmol} / \mathrm{L}$ ) performed on separate days with concomitant infusions of the GLP-1 analog exenatide or with saline, respectively. Continuous measurements of metabolites and counter-regulatory hormones as well as assessments of heart rate variability and symptoms of hypoglycemia were performed throughout the clamps.

Results: No effect of GLP-1 receptor activation on counter-regulatory hormones (glucagon, catecholamines, cortisol, $\mathrm{GH}$ ) or glucose infusion rate was seen, but we found indications of a downregulation of the sympathetic relative to the parasympathetic nerve activity, as reflected in heart rate variability. No significant differences in symptom of hypoglycemia were observed.

Conclusions/interpretation: Short-term exposure to a GLP-1 receptor agonist does not seem to impact the counterregulatory hormonal and metabolic responses in post-GBP subjects during hypoglycemic conditions, suggesting that the improvement in symptomatic hypoglycemia post-GBP seen following treatment with GLP-1 receptor agonists may be mediated by mechanism not directly involved in counter-regulation.
\end{abstract}

\section{Introduction}

Obesity is described by the WHO as an epidemic, affecting people worldwide with profound impact on health. Bariatric surgery is currently the most effective treatment for morbid obesity, and the Roux-en-Y gastric bypass (GBP) surgery is, in competition with gastric sleeve surgery, the most utilized technique worldwide. GBP surgery induces marked weight loss, typically 70-80\% of excess BMI with associated metabolic effects. Most notably, there is a powerful reduction in the risk for future type 2 diabetes (T2D) and frequent remission of preexisting diabetes is seen in up to $70 \%$ (1). A combination of mechanisms are thought to contribute to the beneficial effects of GBP surgery on glucose metabolism. Most food nutrients, including glucose, are absorbed faster after a meal post surgery, and the rise in glucose and insulin is 50\% higher (2). The dynamics of incretins glucose-dependent insulinotropic

Published by Bioscientifica Ltd. 
polypeptide (GIP) and glucagon-like peptide 1 (GLP-1) are changed. A multitude of studies have consistently reported increases, up to ten-fold, in postprandial GLP-1 levels following GBP surgery. The literature is less unanimous regarding the effects of GBP on GIP secretion, where some studies report increases, others report decreases or no effect (3). The explanation behind lower glucose levels post GBP is not fully elucidated, and other suggested mechanisms include changes to gut microbiota, bile acid secretion, hepatic or intestinal glucose handling, splanchnic blood flow, adipose functions and central nervous or autonomic nerve signaling $(4,5,6,7)$.

Putatively, some of the mechanisms that give rise to improved glycemic control may also be the factors underlying the postprandial hypoglycemia that is observed in some patients after GBP surgery. This complication, sometimes described as hyperinsulinemic hypoglycemia syndrome, also occurs after bariatric surgery with other techniques $(8,9)$. Symptoms of postprandial hypoglycemia may be burdensome, occurring $1-4 \mathrm{~h}$ after a meal and consisting of typical hypoglycemic symptoms such as weakness, sweating, dizziness, fainting and in the worst cases seizures and unconsciousness. The prevalence of this syndrome is largely unknown and the reported numbers varies substantially between different studies, ranging from 0.1 to $75 \%$ depending on method used (8, $10,11,12)$. When examining post-GBP patients without complaints of hypoglycemia with continuous glucose monitoring (CGM) our group could report hypoglycemic episodes (glucose $<3.3 \mathrm{mmol} / \mathrm{L}$ ) in $53 \%$ of patients, the majority without any symptoms (8). A temporal mismatch between glucose absorption and insulin as well as incretin secretion is believed to contribute to the development of postprandial hypoglycemia after bariatric surgery (13).

There are unfortunately no clinical randomized trials regarding treatment of this syndrome, but several case reports concerning drugs used off-label. These include acarbose, calcium channel antagonists (14), somatostatin analogs octreotide and pasireotide (15), beta cell inhibitor diazoxide (16) and glucagon (17). We have reported successful treatment with GLP-1 receptor analogs (GLP1-RA) (18) and this has subsequently been observed in cases reported by others $(19,20)$. Moreover, we reported a rise in GLP-1 levels during hypoglycemic clamps in obese subjects, and this was attenuated after GBP (21). Importantly, a propensity to general glucose lowering following GBP might partly be explained by less counter-regulatory responses. This can have beneficial effects in several patients by preventing (or reversing) type 2 diabetes $(7,21)$.
Considering that endogenous GLP-1 has traditionally been regarded as a strong inhibitor of glucagon secretion during hyperglycemia, it is interesting that Degn et al. demonstrated a stimulatory effect of exogenous GLP1-RA during hypoglycemia in healthy subjects (22).

We performed this study in patients about one year after GBP in order to investigate effects of an infusion of the same GLP1-RA, exenatide, on counter-regulatory responses against hypoglycemia. We hypothesized that the observed beneficial effect of GLP1-RA on postprandial hypoglycemia after GBP could be secondary to a biphasic action on glucagon secretion (like the effect of GIP), shifting from inhibitory to stimulatory during hypoglycemia.

\section{Methods}

This study was conducted at the Uppsala University Hospital and the Department of Medical Sciences at Uppsala University. We included subjects who had undergone a laparoscopic gastric bypass surgery about 12 months prior to the study. None had reported symptoms of postprandial hypoglycemia. Exclusion criteria were history of type 1 or type 2 diabetes, cardiovascular disease, pregnancy, previous GLP-1 RA use or any other condition that was deemed to be unsafe or to potentially interfere with the results of the experiment. Subjects were approached in connection with their regular clinical 1-year follow-up at the Metabolic Outpatient Clinic at Uppsala University Hospital. On the days of the experiment, baseline anthropometrics were obtained and body composition was assessed using bioimpedance (Tanita body composition analyzer, BC-418). Heart rate and heart rate variability was measured at baseline and throughout the clamps with custom-made ECG recording system (developed at Biomedical engineering, R\&D, University Hospital Umeå, Sweden). All protocols were followed strictly in accordance with the manufacturer's instructions.

\section{Clamp procedure}

Each subject took part in hyperinsulinemic, hypoglycemic clamps on two separate occasions. The clamp was conducted in parallel with an infusion of either exenatide or saline and this was repeated after 1-4 weeks with an infusion of the other agent. The order of the two experimental conditions was randomized and the subjects were blinded to the infusion given. 
The clamps were performed as previously described (23), modified by our group during previous clamp experiments (21). For clamp design see Fig. 1. Baseline blood samples were drawn after an overnight fast before clamp start. Venous blood samples used for glucose analysis were drawn from an arterialized vein (the subject's hand placed on a heating gel pack). Glucose levels were determined every $5 \mathrm{~min}$ with a Contour Glucose Meter (Bayer Healthcare, Leverkusen, Germany).

The clamp was initiated at minute 0 through the simultaneous priming infusion of insulin (Actrapid, Novo Nordisk Scandinavia, Malmö, Sweden) and exenatide (BYETTA, AstraZeneca AB, Södertälje, Sweden) at $0.066 \mathrm{pmol} / \mathrm{kg} / \mathrm{min}$ or saline. A variable infusion of glucose $(200 \mathrm{mg} / \mathrm{mL})$ was started at the same time to achieve a blood glucose level of $5 \mathrm{mmol} / \mathrm{L}$. An infusion of potassium chloride $(8.0 \mathrm{mmol} / \mathrm{h})$ was given to counteract insulin-induced hypokalemia. After $10 \mathrm{~min}$, the insulin infusion rate was fixed at $56 \mathrm{mU} / \mathrm{m}^{2} \mathrm{BSA} / \mathrm{min}$.

Blood glucose was clamped at $5.0 \mathrm{mmol} / \mathrm{L}$ for the first $60 \mathrm{~min}$ of the experiment. At 60, 90 and $135 \mathrm{~min}$ the glucose infusion rate was lowered to reach a blood glucose concentration of $4.0,3.2$ and $2.7 \mathrm{mmol} / \mathrm{L}$ respectively. At $165 \mathrm{~min}$ the insulin and exenatide/saline infusion was terminated and blood glucose levels were allowed to rise through the glucose infusion at a fixed rate $(200 \mathrm{mg} / \mathrm{kg} / \mathrm{h})$. The glucose infusion was maintained until the subject's blood glucose concentration was above $5 \mathrm{mmol} / \mathrm{L}$ on two repeated measurements.

Arterialized blood samples were drawn from at 0 , $60,90,120,135,150,165$ and $195 \mathrm{~min}$. The glucose infused was recorded every $15-20 \mathrm{~min}$ to calculate glucose infusion rate per $\mathrm{kg}$ fat free mass ( $\mathrm{mg} / \mathrm{kg} \mathrm{FFM} / \mathrm{min}$ ).

To compare symptoms of hypoglycemia, subjects were asked to assess their symptoms on scales from 1 to 7 according to the Edinburgh Hypoglycemia Symptom Scale

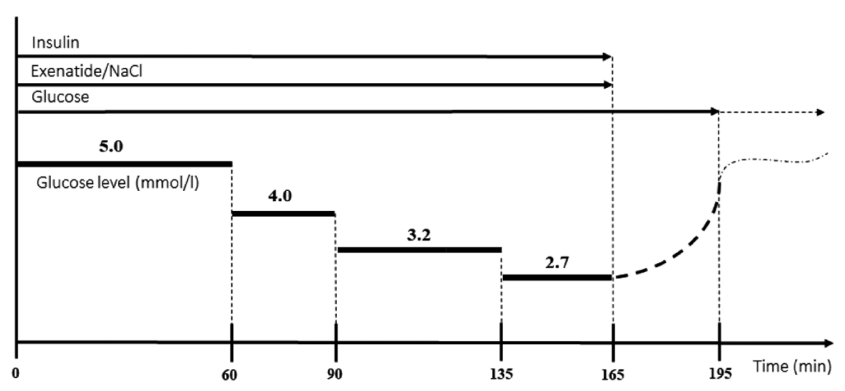

Figure 1

Schematic overview of the hyperinsulinemic-hypoglycemic clamp.
(Supplementary Table 1, see section on supplementary data given at the end of this article) at 0, 135, 150 and $195 \mathrm{~min}$. The symptoms were arranged in subscales, 'autonomic', 'neuroglycopenic', 'malaise', in accordance with the original authors' subdivisions $(24,25)$.

\section{Biochemical measurements}

Routine blood tests were analyzed at the Department of Clinical Chemistry at the Uppsala University Hospital, Sweden. Glucose levels were determined via a hexokinase method (Architect; Abbott). For hormones the following analyses were used: insulin, cortisol and C-peptide (Cobas e; Roche), GH (Immulite 2000XPi; Siemens Healthcare Global). Other analyses were performed at the Clinical Diabetes Research Laboratory. If not analyzed immediately, samples were frozen at $-80^{\circ} \mathrm{C}$. Glucagon, GIP and GLP-1 were collected in $\mathrm{BD}^{\mathrm{TM}} \mathrm{P} 800$ tubes with protease-, esteraseand DPP IV-inhibitors (Becton, Dickinson and Company). ELISA was performed to measure glucagon (\#10-1271-01; Mercodia, Uppsala, Sweden) and total GIP (\#EZHGIP54K; Merck Millipore). For active GLP-1 analysis, the V-PLEX GLP-1 Active kit was used (Meso Scale Discovery (MSD®), Meso Scale Diagnostics, Rockville, MD, USA). Nonesterified fatty acids were measured with the Free Fatty Acid Fluorometric Assay Kit (Cayman Chemical). Glycerol was measured with Free Glycerol reagent (Sigma-Aldrich). All assays, absorbance or fluorescence, were read using a microplate reader (Infinite®200 PRO, Tecan, Männedorf, Switzerland). Adrenaline and noradrenaline levels were determined at the Karolinska University Hospital Laboratory in Huddinge, Sweden, using the Thermo Dionex UltiMate 3000 automated system (Thermo Fisher Scientific) and DECADE II Electrochemical Detector (Antec Scientific, Zoeterwoude, the Netherlands) for highperformance liquid chromatography.

\section{Heart rate variability analysis}

R-R intervals were extracted from the recorded ECG:s and transformed into an evenly sampled $(2 \mathrm{~Hz})$ heart rate time series by cubic spline interpolation. HRV was analyzed by power spectrum analysis of R-R intervals related to normal sinus rhythm using Welch's periodogram method. The total spectral power (PTOT), the power of the low frequency (PLF, 0.04-0.15 Hz), and high frequency (PHF, $0.15-0.50 \mathrm{~Hz}$ ), all $\log$-transformed, were calculated over consecutive 5 -min periods from the complete recording. Since PHF mainly reflects the parasympathetic part while PLF reflects a combination of sympathetic and 
parasympathetic activity, the ratio PLF/PHF was used as a marker of the balance between sympathetic and parasympathetic activity. The HRV analysis was performed using the Matlab Software (MathWorks, Natick, MA, USA).

\section{Statistical analysis}

There was no formal power calculation in this exploratory investigation. However, the power to detect a $15 \%$ difference in glucagon levels is estimated at 90\%, and it is likely to be similar for other clinically relevant hormonal and autonomic nerve changes $(21,26)$. Timevariant changes in HRV were modeled using generalized additive mixed effects models using thin plate splines (27). Differences between recordings during saline and exenatide conditions were modeled as a categorical variable. Differences during normoglycemic (0-60 min) and hypoglycemic phases (90-165 min) were evaluated by analysis of variance for repeated measurements. Other outcomes were analyzed using linear mixed models, except for Edinburgh Hypoglycemia subscales which were analyzed using mixed effects Poisson regressions. A sensitivity analysis of subscales was performed using mixed effects ordinal regression. Our explanatory variables were time (as a categorical variable), treatment and time-treatment interactions.

Glycerol, FFA, glucagon, GIP, adrenaline, noradrenaline and active GLP-1 concentrations were log-transformed before analysis. Back-transformation to original scale was made, and plots for concentrations display the geometric mean. Analyses were performed in Stata 14 (StataCorp. 2015. College Station, TX), R (R ver. 3.5.0, 2018, Vienna, Austria) and Microsoft Excel. For further statistical details, see Supplementary data.

\section{Ethics}

All study procedures were performed in accordance with the Declaration of Helsinki. The Local Ethics Committee of Uppsala gave their approval (DNR 2013/480). The subjects were informed of the planned procedures in verbal and written format and signed an informed consent form.

\section{Results}

Thirteen subjects were recruited, seven females and six males. One female subject underwent the first clamp but then left the study for personal reasons. Her results have been omitted from the analysis. Table 1 shows
Table 1 Subject characteristics $(n=12)$. Post-operative column represents the first visit in the study, approx. 12 months after GBP. Pre-operative column show the latest measures obtained before GBP surgery (retrospectively from medical records). Data are means ( \pm s.D.) or $n$. $P$ value calculated from Student's $T$-test (paired two-sample analysis) comparing pre-operative data with first clamp.

\begin{tabular}{l}
\hline Variable \\
\hline Age (years) \\
Sex M:F \\
Weight $(\mathrm{kg})$ \\
BMI (kg/m²) \\
Fat $(\%)$ \\
FFM (\%) \\
Systolic BP (mmHg) \\
Diastolic BP (mmHg) \\
Resting heart rate (bpm) \\
Fasting glucose (mmol/L) \\
HbA1c (mmol/mol IFCC) \\
HbA1c (\% NGSP) \\
Cholesterol (mmol/L) \\
HDL (mmol/L) \\
LDL (mmol/L) \\
TG (mmol/L)
\end{tabular}

\begin{tabular}{c}
\hline Pre-operative \\
\hline $40.5 \pm 7.2$ \\
$6: 6$ \\
$119.0 \pm 15.9$ \\
$39.8 \pm 3.7$ \\
- \\
- \\
$126 \pm 10$ \\
$81 \pm 7$ \\
- \\
$6.1 \pm 0.9$ \\
$38.2 \pm 6.8$ \\
$5.5 \pm 0.6$ \\
$5.3 \pm 0.8$ \\
$1.1 \pm 0.4$ \\
$3.6 \pm 1.0$ \\
$2.0 \pm 1.0$
\end{tabular}

\begin{tabular}{|c|c|}
\hline Post-operative* & $P$ value \\
\hline \multicolumn{2}{|l|}{$\begin{array}{c}41.8 \pm 6.8 \\
6: 6\end{array}$} \\
\hline $83.3 \pm 11.4$ & $<0.001$ \\
\hline $28.1 \pm 3.6$ & $<0.001$ \\
\hline \multicolumn{2}{|l|}{$28.6 \pm 8.6$} \\
\hline \multicolumn{2}{|l|}{$71.4 \pm 8.6$} \\
\hline $120 \pm 11$ & 0.24 \\
\hline $78 \pm 13$ & 0.43 \\
\hline \multicolumn{2}{|l|}{$64.8 \pm 12.9$} \\
\hline $5.7 \pm 0.6$ & 0.05 \\
\hline $33.5 \pm 2.1$ & 0.03 \\
\hline $5.2 \pm 0.2$ & 0.02 \\
\hline $4.1 \pm 0.5$ & $<0.001$ \\
\hline $1.3 \pm 0.3$ & 0.41 \\
\hline $2.5 \pm 0.7$ & $<0.001$ \\
\hline $0.9 \pm 0.2$ & 0.02 \\
\hline
\end{tabular}

$\mathrm{BMI}$, body mass index; BP, blood pressure; Bpm, beats per minute; FFM, fat free mass; HbA1c, glycated hemoglobin; TG, triglycerides.

* Day of first study visit

anthropometric and metabolic characteristics of the 12 completing participants before their GBP and on the first clamp day.

\section{Blood pressure, heart rate and heart rate variability}

Heart rate and blood pressure data can be viewed in Fig. 2 with exact values presented in Supplementary Table 2. Heart rate increased during hypoglycemia relative to baseline for both conditions respectively. When comparing saline to exenatide (change from baseline), there was a significant difference at time points $60 \mathrm{~min}(P=0.03)$, $90 \mathrm{~min}(P=0.03), 120 \mathrm{~min}(P=0.03)$ and $150 \mathrm{~min}(P=0.05)$ (Fig. 2A). No statistically significant change in systolic blood pressure (Fig. 2B) was observed in either condition and no significant differences between exenatide and saline were observed. Diastolic blood pressure (Fig. 2C) dropped compared to baseline during both conditions. There were no significant differences when comparing saline to exenatide (change from baseline).

The heart rate variability recordings are presented in Fig. 3 and Table 2. The power of low frequency registrations (Fig. 3A) was lower during exenatide infusion, relative to saline, with curves diverging after approximately 

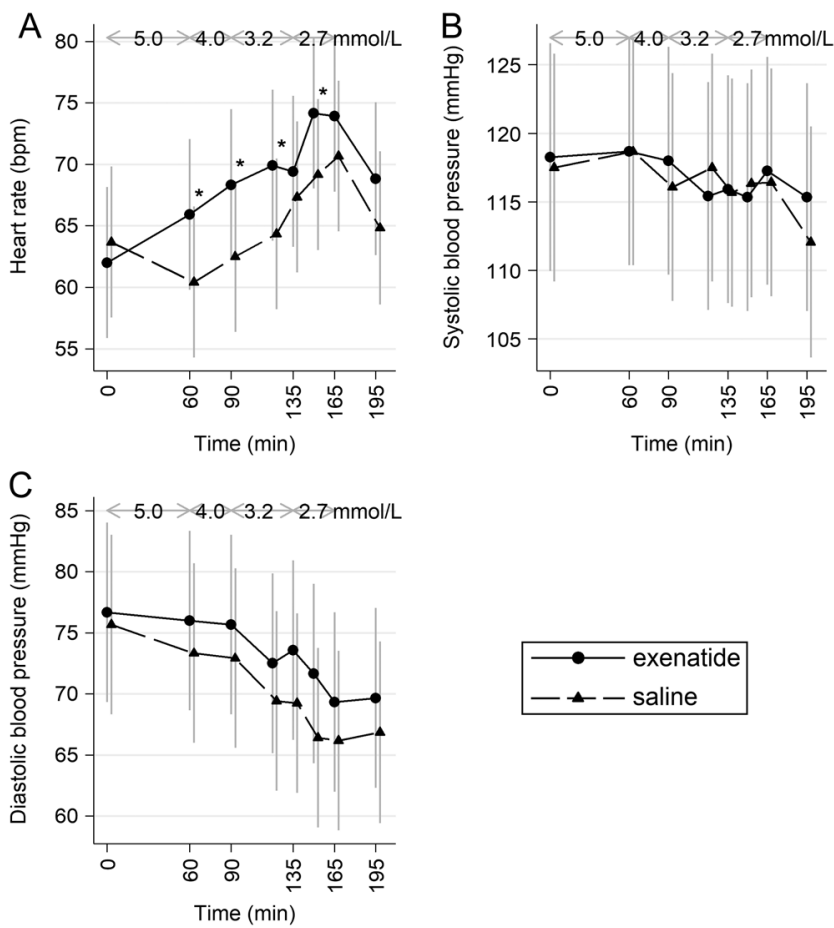

Figure 2

Heart rate $(A)$, systolic $(B)$ and diastolic $(C)$ blood pressure during hypoglycemic clamps. bpm, beats per minute. Data are mean and $95 \%$ confidence interval. ${ }^{*} P<0.05$ for exenatide vs saline.

$30 \mathrm{~min}$, and the difference was statistically significant at 90-165 min, that is during hypoglycemia. The power of the high frequency component (Fig. 3B) was higher for exenatide versus saline throughout the experiment, with a statistically significant difference during normoglycemia but not hypoglycemia. Thus, the composite measure of low frequency to high frequency ratio (Fig. 3C) was lower for exenatide, significantly so during both normoglycemia (0-60 min) and hypoglycemia (90-165 min).

\section{Glucose, insulin, GIR, C-peptide, free fatty acids and glycerol}

For hormone and metabolite levels with comparative $P$ values at specific time points please consult Supplementary Table 2. As expected, the concentrations of glucose (Fig. 4A) and insulin (Fig. 4B) changed similarly for both exenatide and saline during the clamp phases. The glucose infusion rate (GIR) (Fig. 4C) per kg fat free mass was similar for both conditions and no statistically significant differences were observed.

The C-peptide concentration (Fig. 4D and Supplementary Table 2) was consistently and significantly higher throughout exenatide infusion, compared to saline, peaking at $60 \mathrm{~min}$, although the difference became smaller through the hypoglycemic and recovery phases.

There were no statistically significant differences between exenatide and saline in circulating free fatty acid (FFA) levels (Fig. 4E). FFA concentrations were distinctly lowered at $60 \mathrm{~min}$ for both conditions and remained low until $165 \mathrm{~min}$. Levels rose again during recovery. A similar pattern was seen for glycerol (Fig. 4F).

\section{Counter-regulatory hormone levels}

Glucagon levels increased during hypoglycemia for both conditions individually (Fig. 5A). There was no statistically significant difference in change from baseline between exenatide and saline. Details are shown in Supplementary Table 2.

Levels of adrenaline (Fig. 5B) and noradrenaline (Fig. 5C) rose during hypoglycemia phase for both conditions respectively. No significant differences between exenatide and saline were seen for either adrenaline or noradrenaline when comparing change from baseline.

Cortisol levels (Fig. 5D) increased during hypoglycemia for both exenatide and saline which could be observed after $120 \mathrm{~min}$ and onwards. There were no significant differences in cortisol concentrations compared to baseline between exenatide and saline at any time point.

A rise in GH levels (Fig. 5E) was detected from 120 min onwards for both conditions. During infusion with exenatide, the $\mathrm{GH}$ concentration curve diverged downwards from the saline curve at $135 \mathrm{~min}$ but the difference between exenatide and saline for the $\mathrm{GH}$ concentration was not significant at any time point.

GIP levels were lower during exenatide infusion versus saline (Fig. 5F). At 120 and $150 \mathrm{~min}$ the change from baseline in GIP concentration was significant when comparing exenatide and saline.

Active GLP-1 levels decreased during the clamp for both conditions, more so for saline. When comparing change from baseline for exenatide vs saline, the difference was significant at time point 60, 120 and 165, there was however a significant difference $(P=0.03)$ between SAL and EXE already at baseline (Supplementary Fig. 1).

\section{Edinburgh Hypoglycemia Symptom Scale}

While the scores of the Edinburgh Hypoglycemia Symptom Scale (Table 3) increased during hypoglycemia for both conditions, we observed no statistically significant difference when comparing conditions (change from 
A

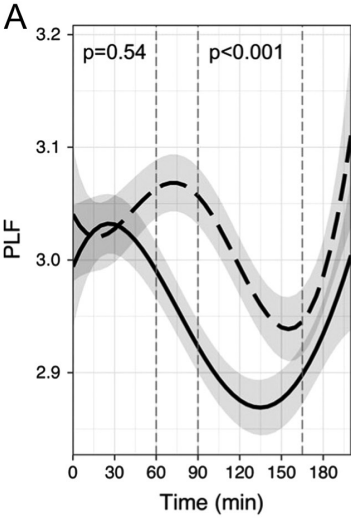

B

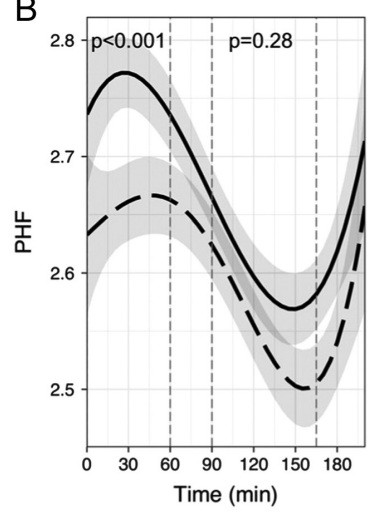

C

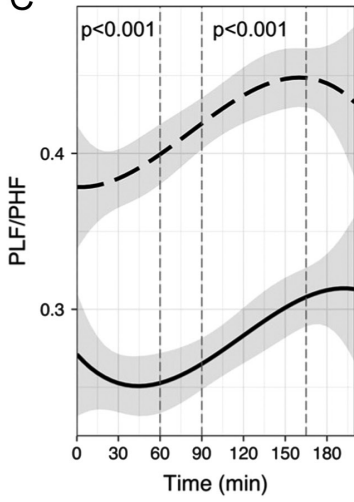

Figure 3

Heart rate variability spectral components during hypoglycemic clamps for exenatide (solid lines) and saline (dashed lines). PLF, power of low frequency component (A); PHF, power of high frequency component (B); PLF/PHF, ratio (C). Values are $\mathrm{ms}^{2}$ (log) and the shaded areas indicate S.E.M. $P$ values refer to differences between exenatide and saline during normoglycemia (0-60 min) and during hypoglycemia (90-165 min), respectively. baseline to hypoglycemia). Neuroglycopenic symptoms of hypoglycemia were lower for exenatide, but the difference was non-significant $(P=0.30)$; the same was true for autonomic nervous symptoms $(P=0.82)$ and symptoms of malaise $(P=0.84)$. The results were similar for the sensitivity analysis with a mixed effects ordinal logistic model (data not shown).

\section{Discussion}

In order to elucidate actions of endogenous GLP-1 and its receptors on hypoglycemic counter-regulation in post-GBP patients, we utilized an exogenous GLP-1 RA and studied its effects during hypoglycemic clamps. We hypothesized that the reduced GLP-1 secretion during hypoglycemia seen in post-GBP patients (21), contributes to an attenuated hypoglycemic counter-regulation after surgery and that activation of GLP-1 receptors by

Table 2 Heart rate variability analysis. Data are means

(s.E.M.).

\begin{tabular}{|c|c|c|c|}
\hline Variable & Saline & Exenatide & P value \\
\hline \multicolumn{4}{|c|}{ Normoglycemia (0-60 min) } \\
\hline $\mathrm{RR}(\mathrm{s})$ & $0.96(0.05)$ & $0.96(0.01)$ & 0.35 \\
\hline$P_{\text {tot }}\left(\mathrm{ms}^{2}, \mathrm{log}\right)$ & $3.50(0.07)$ & $3.52(0.02)$ & 0.48 \\
\hline $\mathrm{P}_{\mathrm{LF}}\left(\mathrm{ms}^{2}, \log \right)$ & $3.03(0.07)$ & $3.02(0.02)$ & 0.54 \\
\hline $\mathrm{P}_{\mathrm{HF}}\left(\mathrm{ms}^{2}, \mathrm{log}\right)$ & $2.65(0.07)$ & $2.76(0.02)^{\star \star \star}$ & $<0.001$ \\
\hline $\mathrm{P}_{\mathrm{LF}} / \mathrm{P}_{\mathrm{HF}}(\mathrm{log})$ & $0.38(0.03)$ & $0.26(0.02)^{* \star *}$ & $<0.001$ \\
\hline \multicolumn{4}{|c|}{ Hypoglycemia (90-165 min) } \\
\hline $\mathrm{RR}(\mathrm{s})$ & $0.93(0.05)$ & $0.87(0.01)^{\star \star *}$ & $<0.001$ \\
\hline$P_{\text {tot }}\left(\mathrm{ms}^{2}, \log \right)$ & $3.47(0.07)$ & $3.42(0.02)^{*}$ & 0.03 \\
\hline$P_{L F}\left(m s^{2}, \log \right)$ & $2.98(0.06)$ & $2.88(0.02)^{\star \star \star}$ & $<0.001$ \\
\hline $\mathrm{P}_{\mathrm{HF}}\left(\mathrm{ms}^{2}, \mathrm{log}\right)$ & $2.55(0.08)$ & $2.58(0.03)$ & 0.28 \\
\hline $\mathrm{P}_{\mathrm{LF}} / \mathrm{P}_{\mathrm{HF}}(\log )$ & $0.44(0.05)$ & $0.30(0.02)^{\star \star *}$ & $<0.001$ \\
\hline
\end{tabular}

Spectral indices are log-transformed.

$\star P<0.05, * \star \star P<0.001$ for exenatide vs saline.

$\mathrm{P}_{\mathrm{HF}}$, power of high frequency component; $\mathrm{P}_{\mathrm{LF}}$, power of low frequency component; $P_{\text {tot }}$ total power; $R R$, mean RR interval. an exogenous GLP-1 RA infused during hypoglycemic clamps would increase glucagon levels, as suggested by some previous work (28).

However, the hypothesis was not supported by these experiments. Exenatide compared to saline infusion did not alter GIR values throughout the stepwise hypoglycemia or during the recovery phase, indicating that there was no change in glucose turnover promoting recovery toward normoglycemia. Overall, the response of the traditional counter-regulatory hormones (glucagon, cortisol, catecholamines, growth hormone) to hypoglycemia were in accordance with previous studies on post-gastric bypass patients $(21,29)$, but this did not differ for exenatide vs saline infusions. Foremost, the hormone that had been implicated as a possible mediator, glucagon, was not affected by exenatide.

Endogenous GLP-1 has a strong inhibitory effect on glucagon secretion, but this is thought to be mediated largely by paracrine effects of insulin and somatostatin, the secretion of which are both stimulated by GLP-1 (30). As for exogenous administration of GLP-1 RA, several studies have shown suppression of glucagon secretion vs placebo during normo- and hyperglycemia, particularly in the postprandial state $(28,31,32)$. A glucose dependency of this effect is supported by studies in which no GLP-1 RA-mediated suppression of glucagon could be seen in during hypoglycemic, but in some cases also normoglycemic, clamps (33, 34, 35, 36). However, suppression of glucagon secretion during mild hypoglycemia (glucose $3.2-5.0 \mathrm{mmol} / \mathrm{L}$ ) that was not evident during more pronounced hypoglycemia (glucose $<3.0 \mathrm{mmol} / \mathrm{L}$ ) have also been reported in some studies $(22,37,38)$. On the contrary, Degn et al. reported a 30\% glucagon increase with GLP-1 RA vs placebo in healthy subjects at the nadir glucose level of $2.7 \mathrm{mmol} / \mathrm{L}$ (22). In our present study, we did not observe a similar glucagon response to GLP-1 RA exposure in patients who 

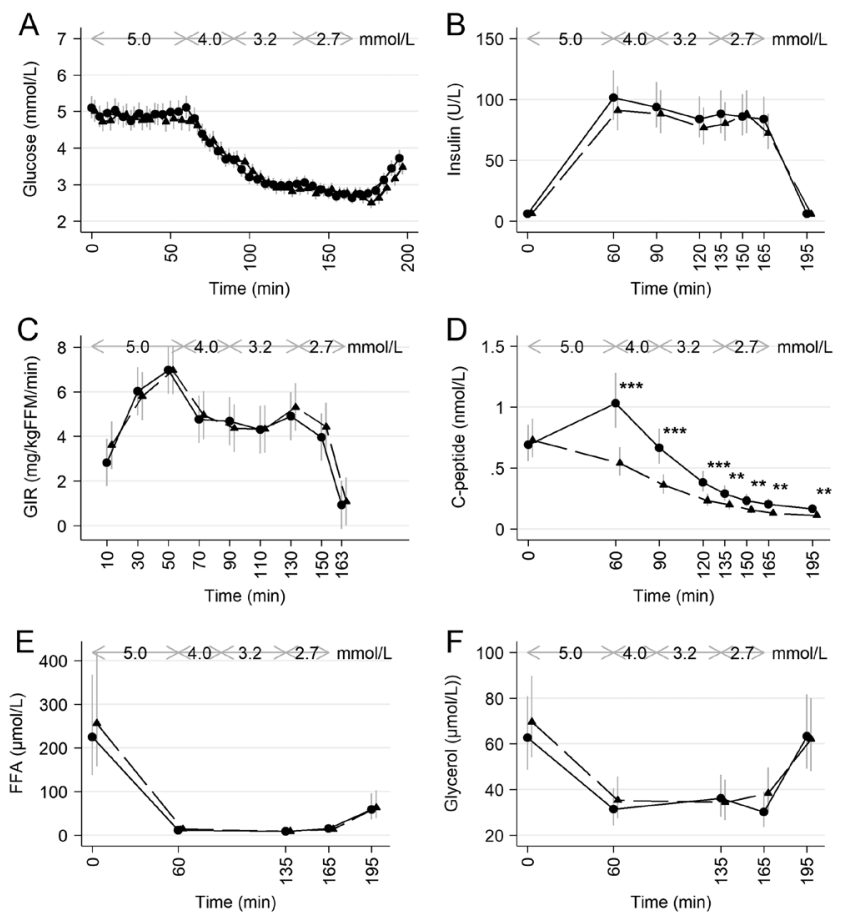

$\bullet$ exenatide $-\llcorner-$ saline

\section{Figure 4}

Levels of glucose (A), insulin (B), C-peptide (D), FFA (E) and glycerol (F) and GIR (C) during hypoglycemic clamps and concomitant infusion with exenatide and saline, respectively. GIR, glucose infusion rate. FFA, free fatty acids. Data are geometric mean and $95 \%$ confidence interval. $* P<0.05$, $\star * P<0.01$ and $* * * P<0.001$ for exenatide vs saline.

had undergone bariatric surgery. Thus, the glucagon levels did not differ at any phase of the normoglycemichypoglycemic clamp with concomitant exenatide vs saline infusion.

One finding of this study was the lower levels of the incretin hormone GIP observed with exenatide infusion compared to saline. This is in keeping with some other studies which observed lower post-meal GIP with GLP-1 infusion compared to saline $(39,40)$ and with 3 months of exenatide treatment compared to baseline (41). Taken together, these findings could be suggestive of a negative feedback mechanism of GLP-1/GLP-1 RA on GIP secretion.

There was an expected significant increase in C-peptide and a non-significant trend toward increased insulin levels. C-peptide concentrations, albeit sinking during hypoglycemia, remained significantly higher for exenatide vs saline throughout the experiment. GLP-1 is considered to stimulate glucose-dependent insulin secretion and the effect on insulin secretion as measured
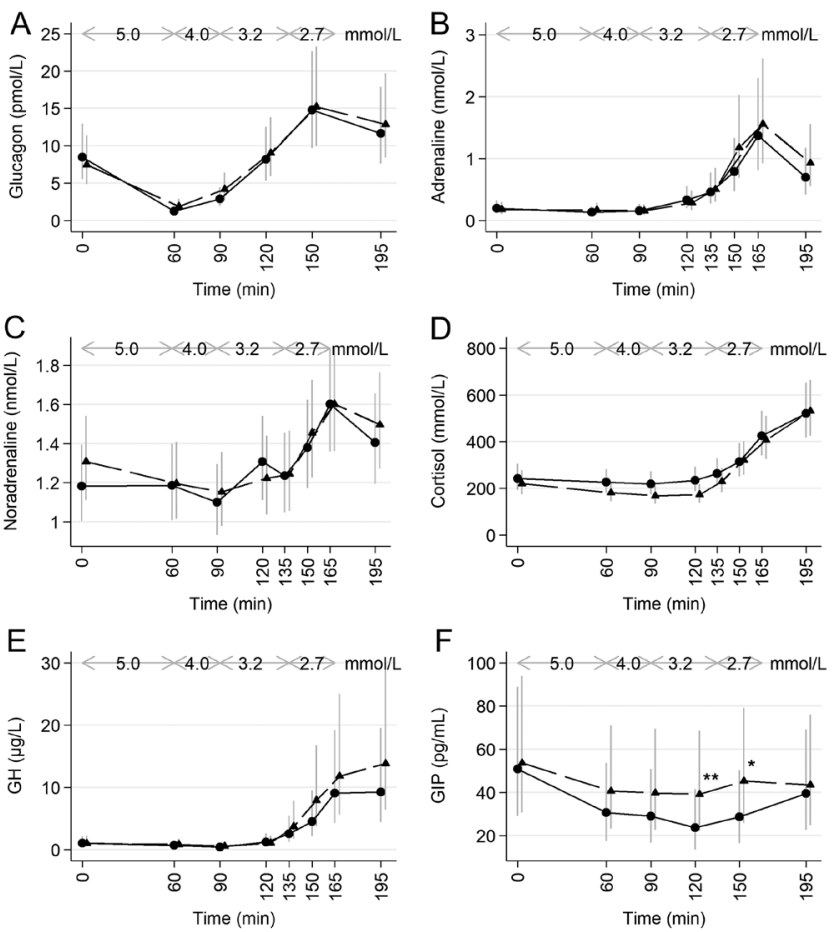

$\longrightarrow$ exenatide $\_--$saline

\section{Figure 5}

Hormone levels during hypoglycemic clamps and concomitant infusion with exenatide and saline, respectively. Glucagon (A), adrenaline (B), noradrenaline (C), cortisol (D), GH (E) and GIP

(F). GH, growth hormone. GIP, glucose-dependent insulinotropic polypeptide. Data are geometric means and 95\% confidence intervals. ${ }^{*} P<0.05, * * P<0.01$ and $\star * \star P<0.001$ for exenatide vs saline.

by C-peptide levels should therefore decrease during hypoglycemia. However, C-peptide has a relatively long half-life of $20-30 \mathrm{~min}$ and we therefore believe that the observed elevation during hypoglycemia is more likely explained by remaining C-peptide secreted during the normoglycemic phase rather than by de novo insulin secretion during hypoglycemia.

We also performed assessments of autonomic nerve activity as reflected in heart rate variability. The PLF/PHF ratio was lower for exenatide than for saline throughout the clamp experiments, whereas PLF was reduced during hypoglycemia and PHF was increased in particular during normoglycemia. As PLF is considered to reflect a combination of sympathetic and parasympathetic activity, the results could be interpreted as a combination of an attenuation of sympathetic activity during hypoglycemia, and an increase in parasympathetic activity, mainly during normoglycemia. However, we cannot definitely 
Table 3 Edinburgh Hypoglycemia Symptom Scale scores. Data are means, 95\% confidence intervals for total score and subscale scores of the Edinburgh Hypoglycemia Symptom Scale. Subscores analyzed with Poisson regression analysis. $P$ values comparing change from baseline (before clamp start) for exenatide versus saline.

\begin{tabular}{l}
\hline Variable \\
\hline Autonomic \\
Saline \\
Exenatide \\
$P$ value \\
Neuroglycopenic \\
Saline \\
Exenatide \\
$P$ value \\
Malaise \\
Saline \\
Exenatide \\
$P$ value \\
Total Score \\
Saline \\
Exenatide \\
\hline
\end{tabular}

\begin{tabular}{|c|c|}
\hline Baseline & Hypoglycemia \\
\hline $5.5(4.3-7.1)$ & $9.7(8.0-11.9)$ \\
\hline $4.9(3.8-6.5)$ & $8.3(6.7-10.3)$ \\
\hline- & 0.82 \\
\hline $5.3(4.2-6.8)$ & $8.1(6.6-9.9)$ \\
\hline $6.5(5.2-8.1)$ & $7.8(6.4-9.6)$ \\
\hline- & 0.30 \\
\hline $2.0(1.3-3.1)$ & $2.7(1.9-3.9)$ \\
\hline $2.4(1.6-3.6)$ & $3.0(2.1-4.3)$ \\
\hline- & 0.84 \\
\hline $13.0(9.8-16.2)$ & $20.8(17.6-24.0)$ \\
\hline $14.0(10.8-17.2)$ & 18.5 (15.3-21.7) \\
\hline
\end{tabular}

\begin{tabular}{c}
\hline ES $(\mathrm{Cl})$ hypo vs baseline \\
\hline $1.77(1.31-2.39)^{*}$ \\
$1.68(1.22-2.32)^{*}$ \\
\\
$1.52(1.11-2.08)^{\star}$ \\
$1.21(0.89-1.63)^{\star}$ \\
$1.36(0.81-2.28)^{\star}$ \\
$1.27(0.78-2.04)^{\star}$ \\
$7.8(4.1-11.4)^{\dagger}$ \\
$4.5(0.9-8.1)^{\dagger}$
\end{tabular}

\begin{tabular}{|c|}
\hline After recovery \\
\hline $\begin{array}{l}8.5(6.8-10.5) \\
7.2(5.8-9.1) \\
0.84\end{array}$ \\
\hline $\begin{array}{l}6.3(5.1-7.9) \\
6.5(5.2-8.1) \\
0.46\end{array}$ \\
\hline $\begin{array}{l}2.9(2.0-4.1) \\
2.8(1.9-4.0) \\
0.56\end{array}$ \\
\hline $\begin{array}{l}17.9(14.7-21.1) \\
15.8(12.6-18.9)\end{array}$ \\
\hline
\end{tabular}

ES $(\mathrm{Cl})$ recovery vs baseline

${ }^{*}$ Ratio, ${ }^{\dagger}$ mean difference.

$\mathrm{Cl}$, confidence interval; $\mathrm{ES}$, effect size.

conclude to what degree specific changes in sympathetic and parasympathetic tone, respectively, contribute. The lower PLF/PHF ratio seen with exenatide was not associated with expected hemodynamic changes. Systolic and diastolic blood pressures were not significantly different, whereas heart rate was significantly higher throughout the experiment with exenatide vs saline. Moreover, we found no difference between circulating levels of adrenaline or noradrenaline in exenatide vs saline. The observed increase in heart rate in this study cannot be explained by the observed effects on sympathovagal tone as reflected by the HRV variables. Studies of GLP-1 RA-mediated autonomic nervous system (ANS) effects have been inconclusive $(42,43,44,45,46$, 47). Nevertheless, it is well established that GLP-1 RA induces a small increase in heart rate and perhaps this can be explained by a direct effect of GLP-1 on the heart, for example on cardiomyocytes in the sinoatrial node, where GLP-1 receptors have been identified in both humans and animals.

Notwithstanding the results of this present study, GLP1-RA treatment in patients with symptomatic, commonly postprandial, hypoglycemia after GBP surgery appears to be of value. Our research group previously reported five cases in which GLP1-RA treatment alleviated symptoms and in the three cases where CGM was utilized, no hypoglycemic episodes was seen during such treatment (18). This is further supported by case reports $(19,20)$ in which symptoms were reduced and hypoglycemia abolished as confirmed by CGM following treatment with liraglutide. Although the current study does not support the hypothesized direct effect of GLP1-RA to stimulate the release of glucagon or other counter-regulatory hormones during hypoglycemia, it does not preclude other beneficial effects on hypoglycemia and associated symptoms. Continuous near-maximal stimulation of GLP-1-receptors with long-term treatment might for example attenuate the effect of the postprandial endogenous GLP-1 peak post surgery. As previously discussed, it is also possible that GLP1-RA treatment may interfere with the regulation of endogenous incretin secretion. Indeed, increased levels of both insulin and GLP-1 in response to a mixed meal test in patients with post-GBP hypoglycemia compared to asymptomatic patients have been demonstrated (20). It remains to be investigated whether exogenous GLP-1 RA attenuates these hormonal fluctuations specifically in the postprandial setting. Finally, inhibition of small bowel motility, resulting in slower nutrient transit, has been demonstrated following GLP-1 RA administration (48) and represents another plausible mechanism.

There are several limitations to this study. The subjects in our study were examined in the fasting state by a hypoglycemic clamp, whereas patients with postprandial hypoglycemia after bariatric surgery typically experience symptoms after meals. In addition, the dynamics of incretin secretion is more influenced by nutrient intake than fluctuations in blood glucose levels per se. Finally, our study participants were recruited at routine follow-up after GBP and none had a history of symptomatic hypoglycemia post-surgery. Thus, patients with clinical 
hypoglycemia could potentially have different hormonal responses and effects of GLP-1 receptor activation compared to the study participants.

In summary, we found no counter-regulatory glucoseraising effects of exogenous GLP1-RA administration during hypoglycemic clamps in post-GBP patients. Thus, the attenuated hypoglycemia counter-regulation previously shown in such patients is probably not explained by their reduced GLP-1 response. Further studies should elucidate the role of GLP-1 during post-GBP hypoglycemia under real-life circumstances, for instance following a meal. Taken together our data suggest that GLP-1 can modulate autonomic nerve activity, but does not have any counter-regulatory glucose-raising effects during hypoglycemia in post-GBP patients.

\section{Supplementary data}

This is linked to the online version of the paper at https://doi.org/10.1530/ EJE-19-0171.

\section{Declaration of interest}

J W E has received research support and honoraria from AstraZeneca and NovoNordisk. The other authors have nothing to disclose.

\section{Funding}

This study was funded by grants from the Swedish Diabetes Foundation, the Ernfors Foundation, EXODIAB and ALF (Swedish Government research grants to the Uppsala University Hospital).

\section{Author contribution statement}

K E A contributed to the design and conduct of the study, interpretation of the results, and writing the manuscript. N A designed the study, contributed to the conduct of the study, interpretation of the results and writing the manuscript. $\mathrm{M} \mathrm{H} \mathrm{L} \mathrm{contributed} \mathrm{to} \mathrm{writing} \mathrm{the} \mathrm{manuscript.}$ $\mathrm{U} \mathrm{H}$ performed statistical analysis and presentation and contributed to writing the manuscript. $\mathrm{K} \mathrm{T}$ and $\mathrm{A} \mathrm{P}$ contributed to the conduct of the study. F A K and M S contributed to writing the manuscript. U W performed heart rate variability analysis and contributed to writing the manuscript. J W E designed the study and contributed to the conduct of the study, interpretation of results and writing the manuscript. All authors reviewed the manuscript and approved the final version.

\section{Acknowledgements}

The authors are grateful to all participants in the study. We thank staff at Clinical Diabetes and Metabolism, Uppsala University and at Uppsala University Hospital for their invaluable support.

\section{References}

1 Ribaric G, Buchwald JN \& McGlennon TW. Diabetes and weight in comparative studies of bariatric surgery vs conventional medical therapy: a systematic review and meta-analysis. Obesity Surgery 2014 24 437-455. (https://doi.org/10.1007/s11695-013-1160-3)
2 Falkén Y, Hellström PM, Holst JJ \& Näslund E. Changes in glucose homeostasis after Roux-en-Y gastric bypass surgery for obesity at day three, two months, and one year after surgery: role of gut peptides. Journal of Clinical Endocrinology and Metabolism 201196 2227-2235. (https://doi.org/10.1210/jc.2010-2876)

3 Laferrère B. Bariatric surgery and obesity: influence on the incretins. International Journal of Obesity Supplements 20166 S32-S36. (https:// doi.org/10.1038/ijosup.2016.8)

4 Salehi M, Gastaldelli A \& D'Alessio DA. Role of vagal activation in postprandial glucose metabolism after gastric bypass in individuals with and without hypoglycaemia. Diabetes, Obesity and Metabolism 201921 1513-1517. (https://doi.org/10.1111/dom.13676)

5 Laferrère B \& Pattou F. Weight-independent mechanisms of glucose control after Roux-en-Y gastric bypass. Frontiers in Endocrinology 2018 9 530. (https://doi.org/10.3389/fendo.2018.00530)

6 Honka H, Koffert J, Kauhanen S, Teuho J, Hurme S, Mari A, Lindqvist A, Wierup N, Groop L \& Nuutila P. Bariatric surgery enhances splanchnic vascular responses in patients with type 2 diabetes. Diabetes 201766 880-885. (https://doi.org/10.2337/db16-0762)

7 Katsogiannos P, Kamble PG, Boersma GJ, Karlsson FA, Lundkvist P, Sundbom M, Pereira MJ \& Eriksson JW. Early changes in adipose tissue morphology, gene expression and metabolism after RYGB in patients with obesity and T2D. Journal of Clinical Endocrinology and Metabolism 2019104 2601-2613. (https://doi.org/10.1210/jc.201802165)

8 Abrahamsson N, Engström BE, Sundbom M \& Karlsson FA. Hypoglycemia in everyday life after gastric bypass and duodenal switch. European Journal of Endocrinology 2015173 91-100. (https:// doi.org/10.1530/EJE-14-0821)

9 Papamargaritis D, Koukoulis G, Sioka E, Zachari E, Bargiota A, Zacharoulis D \& Tzovaras G. Dumping symptoms and incidence of hypoglycaemia after provocation test at 6 and 12 months after laparoscopic sleeve gastrectomy. Obesity Surgery 201222 1600-1606. (https://doi.org/10.1007/s11695-012-0711-3)

10 Kefurt R, Langer FB, Schindler K, Shakeri-Leidenmühler S, Ludvik B \& Prager G. Hypoglycemia after Roux-en-Y gastric bypass: detection rates of continuous glucose monitoring (CGM) versus mixed meal test. Surgery for Obesity and Related Diseases 201511 564-569. (https://doi.org/10.1016/j.soard.2014.11.003)

11 Lee CJ, Clark JM, Schweitzer M, Magnuson T, Steele K, Koerner O \& Brown TT. Prevalence of and risk factors for hypoglycemic symptoms after gastric bypass and sleeve gastrectomy. Obesity 201523 1079-1084. (https://doi.org/10.1002/oby.21042)

12 Sarwar H, Chapman WH, Pender JR, Ivanescu A, Drake AJ, Pories WJ $\&$ Dar MS. Hypoglycemia after Roux-en-Y gastric bypass: the BOLD experience. Obesity Surgery 201424 1120-1124. (https://doi. org/10.1007/s11695-014-1260-8)

13 Øhrstrøm CC, Worm D \& Hansen DL. Postprandial hyperinsulinemic hypoglycemia after Roux-en-Y gastric bypass: an update. Surgery for Obesity and Related Diseases 201713 345-351. (https://doi. org/10.1016/j.soard.2016.09.025)

14 Moreira RO, Moreira RBM, Machado NAM, Gonçalves TB \& Coutinho WF. Post-prandial hypoglycemia after bariatric surgery: pharmacological treatment with verapamil and acarbose. Obesity Surgery 200818 1618-1621. (https://doi.org/10.1007/s11695-0089569-9)

15 de Heide LJM, Laskewitz AJ \& Apers JA. Treatment of severe postRYGB hyperinsulinemic hypoglycemia with pasireotide: a comparison with octreotide on insulin, glucagon, and GLP-1. Surgery for Obesity and Related Diseases 201410 e31-e33. (https://doi. org/10.1016/j.soard.2013.11.006)

16 Gonzalez-Gonzalez A, Delgado M \& Fraga-Fuentes MD. Use of diazoxide in management of severe postprandial hypoglycemia in patient after Roux-en-Y gastric bypass. Surgery for Obesity and Related Diseases 20139 e18-e19. (https://doi.org/10.1016/j. soard.2011.05.010) 
17 Laguna AJ, Mulla CM, Fowler KM, Cloutier E, Goldfine AB, Newswanger B, Cummins M, Deshpande S, Prestrelski SJ, Strange P et al. Design and clinical evaluation of a novel low-glucose prediction algorithm with mini-dose stable glucagon delivery in post-bariatric hypoglycemia. Diabetes Technology and Therapeutics 201820 127-139. (https://doi.org/10.1089/dia.2017.0298)

18 Abrahamsson N, Engström BE, Sundbom M \& Karlsson FA. GLP1 analogs as treatment of postprandial hypoglycemia following gastric bypass surgery: a potential new indication? European Journal of Endocrinology 2013169 885-889. (https://doi.org/10.1530/EJE-13-0504)

19 Chiappetta S \& Stier C. A case report: liraglutide as a novel treatment option in late dumping syndrome. Medicine 201796 e6348. (https:// doi.org/10.1097/MD.0000000000006348)

20 Tharakan G, Behary P, Wewer Albrechtsen NJ, Chahal H, Kenkre J, Miras AD, Ahmed AR, Holst JJ, Bloom SR \& Tan T. Roles of increased glycaemic variability, GLP-1 and glucagon in hypoglycaemia after Roux-en-Y gastric bypass. European Journal of Endocrinology 2017177 455-464. (https://doi.org/10.1530/EJE-17-0446)

21 Abrahamsson N, Börjesson JL, Sundbom M, Wiklund U, Karlsson FA \& Eriksson JW. Gastric bypass reduces symptoms and hormonal responses in hypoglycemia. Diabetes 201665 2667-2675. (https:// doi.org/10.2337/db16-0341)

22 Degn KB, Brock B, Juhl CB, Djurhuus CB, Grubert J, Kim D, Han J, Taylor K, Fineman M \& Schmitz O. Effect of intravenous infusion of exenatide (synthetic Exendin-4) on glucose-dependent insulin secretion and counterregulation during hypoglycemia. Diabetes 2004 53 2397-2403. (https://doi.org/10.2337/diabetes.53.9.2397)

23 Norjavaara E, Ericsson H, Sjöberg F, Leonsson-Zachrisson M, Sjöstrand M, Morrow LA \& Hompesch M. Glucokinase activators AZD6370 and AZD1656 do not affect the central counterregulatory response to hypoglycemia in healthy males. Journal of Clinical Endocrinology and Metabolism 201297 3319-3325. (https://doi. org/10.1210/jc.2012-1496)

24 Deary IJ, Hepburn DA, MacLeod KM \& Frier BM. Partitioning the symptoms of hypoglycaemia using multi-sample confirmatory factor analysis. Diabetologia 199336 771-777. (https://doi.org/10.1007/ BF00401150)

25 McAulay V, Deary IJ, Ferguson SC \& Frier BM. Acute hypoglycemia in humans causes attentional dysfunction while nonverbal intelligence is preserved. Diabetes Care 200124 1745-1750. (https://doi. org/10.2337/diacare.24.10.1745)

26 Lundkvist P, Pereira MJ, Kamble PG, Katsogiannos P, Langkilde AM, Esterline R, Johnsson E \& Eriksson JW. Glucagon levels during shortterm SGLT2 inhibition are largely regulated by glucose changes in patients with type 2 diabetes. Journal of Clinical Endocrinology and Metabolism 2019104 193-201. (https://doi.org/10.1210/jc.201800969)

27 Wood SN. Thin plate regression splines. Journal of the Royal Statistical Society: Series B 200365 95-114. (https://doi.org/10.1111/14679868.00374)

28 Degn KB, Juhl CB, Sturis J, Jakobsen G, Brock B, Chandramouli V, Rungby J, Landau BR \& Schmitz O. One week's treatment with the long-acting glucagon-like peptide 1 derivative liraglutide (NN2211) markedly improves 24 -h glycemia and $\alpha$ - and $\beta$-cell function and reduces endogenous glucose release in patients with type 2 diabetes. Diabetes 200453 1187-1194. (https://doi.org/10.2337/ diabetes.53.5.1187

29 Guldstrand M, Ahrén B, Wredling R, Backman L, Lins PE \& Adamson U. Alteration of the counterregulatory responses to insulininduced hypoglycemia and of cognitive function after massive weight reduction in severely obese subjects. Metabolism: Clinical and Experimental 200352 900-907. (https://doi.org/10.1016/S00260495(03)00103-3)

30 Sandoval DA \& D'Alessio DA. Physiology of proglucagon peptides: role of glucagon and GLP-1 in health and disease.
Physiological Reviews 201595 513-548. (https://doi.org/10.1152/ physrev.00013.2014)

31 Ahrén B, Gautier JF, Berria R, Stager W, Aronson R \& Bailey CJ. Pronounced reduction of postprandial glucagon by lixisenatide: a meta-analysis of randomized clinical trials. Diabetes, Obesity and Metabolism 201416 861-868. (https://doi.org/10.1111/dom.12290)

32 Hare KJ, Knop FK, Asmar M, Madsbad S, Deacon CF, Holst JJ \& Vilsbøll T. Preserved inhibitory potency of GLP-1 on glucagon secretion in type 2 diabetes mellitus. Journal of Clinical Endocrinology and Metabolism 200994 4679-4687. (https://doi.org/10.1210/ jc.2009-0921)

33 Frandsen CS, Dejgaard TF, Andersen HU, Holst JJ, Hartmann B, Thorsteinsson B \& Madsbad S. Liraglutide as adjunct to insulin treatment in type 1 diabetes does not interfere with glycaemic recovery or gastric emptying rate during hypoglycaemia: a randomized, placebo-controlled, double-blind, parallel-group study. Diabetes, Obesity and Metabolism 201719 773-782. (https://doi. org/10.1111/dom.12830)

34 Hompesch M, Jones-Leone A, Carr MC, Matthews J, Zhi H, Young M, Morrow L \& Reinhardt RR. Albiglutide does not impair the counter-regulatory hormone response to hypoglycaemia: a randomized, double-blind, placebo-controlled, stepped glucose clamp study in subjects with type 2 diabetes mellitus. Diabetes, Obesity and Metabolism 201517 82-90. (https://doi.org/10.1111/ dom.12398)

35 Korsatko S, Jensen L, Brunner M, Sach-Friedl S, Tarp MD, Holst AG, Heller SR \& Pieber TR. Effect of once-weekly semaglutide on the counterregulatory response to hypoglycaemia in people with type 2 diabetes: a randomized, placebo-controlled, double-blind, crossover trial. Diabetes, Obesity and Metabolism 201820 2565-2573. (https:// doi.org/10.1111/dom.13422)

36 Pieber TR, Deller S, Korsatko S, Jensen L, Christiansen E, Madsen J \& Heller SR. Counter-regulatory hormone responses to hypoglycaemia in people with type 1 diabetes after 4 weeks of treatment with liraglutide adjunct to insulin: a randomized, placebo-controlled, double-blind, crossover trial. Diabetes, Obesity and Metabolism 2015 17 742-750. (https://doi.org/10.1111/dom.12473)

37 Farngren J, Persson M \& Ahrén B. Effect of the GLP-1 receptor agonist lixisenatide on counterregulatory responses to hypoglycemia in subjects with insulin-treated Type 2 diabetes. Diabetes Care 2016 39 242-249. (https://doi.org/10.2337/dc15-1274)

38 Nauck MA, Heimesaat MM, Behle K, Holst JJ, Nauck MS, Ritzel R, Hüfner M \& Schmiegel WH. Effects of glucagon-like peptide 1 on counterregulatory hormone responses, cognitive functions, and insulin secretion during hyperinsulinemic, stepped hypoglycemic clamp experiments in healthy volunteers. Journal of Clinical Endocrinology and Metabolism 200287 1239-1246. (https://doi. org/10.1210/jcem.87.3.8355)

39 Flint A, Raben A, Ersbøll AK, Holst JJ \& Astrup A. The effect of physiological levels of glucagon-like peptide-1 on appetite, gastric emptying, energy and substrate metabolism in obesity. International Journal of Obesity and Related Metabolic Disorders 200125 781-792. (https://doi.org/10.1038/sj.ijo.0801627)

40 Kielgast U, Holst JJ \& Madsbad S. Antidiabetic actions of endogenous and exogenous GLP-1 in type 1 diabetic patients with and without residual $\beta$-cell function. Diabetes 201160 1599-1607. (https://doi. org/10.2337/db10-1790)

41 Camastra S, Astiarraga B, Tura A, Frascerra S, Ciociaro D, Mari A, Gastaldelli A \& Ferrannini E. Effect of exenatide on postprandial glucose fluxes, lipolysis, and $\beta$-cell function in non-diabetic, morbidly obese patients. Diabetes, Obesity and Metabolism 201719 412-420. (https://doi.org/10.1111/dom.12836)

42 Cacciatori V, Zoppini G, Bellavere F, Rigolon R, Thomaseth K, Pichiri I, Trombetta M, Dauriz M, De Santi F, Targher G et al. Longacting GLP-1 receptor agonist exenatide influence on the autonomic 
cardiac sympatho-vagal balance. Journal of the Endocrine Society 2018 2 53-62. (https://doi.org/10.1210/js.2017-00300)

43 Hara K, Aso Y, Komatsu T, Nakamachi T, Sakai Y, Takayanagi K, Kasai $\mathrm{K} \&$ Inukai T. Liraglutide increases 24 -h heart rate by reducing the cardiac parasympathetic activity of patients with type 2 diabetes: power spectral analysis of heart rate variability on 24-h Holter ECG recordings. Diabetology International 20156 26-32. (https://doi. org/10.1007/s13340-014-0170-2)

44 Kumarathurai P, Anholm C, Larsen BS, Olsen RH, Madsbad S, Kristiansen O, Nielsen OW, Haugaard SB \& Sajadieh A. Effects of liraglutide on heart rate and heart rate variability: a randomized, double-blind, placebo-controlled crossover study. Diabetes Care 2017 40 117-124. (https://doi.org/10.2337/dc16-1580)

45 Nakatani Y, Kawabe A, Matsumura M, Aso Y, Yasu T, Banba N \& Nakamoto T. Effects of GLP-1 receptor agonists on heart rate and the autonomic nervous system using holter electrocardiography and power spectrum analysis of heart rate variability. Diabetes Care 2015 39 e22-e23. (https://doi.org/10.2337/dc15-1437)
46 Smits MM, Muskiet MHA, Tonneijck L, Hoekstra T, Kramer MHH, Diamant $\mathrm{M} \&$ van Raalte DH. Exenatide acutely increases heart rate in parallel with augmented sympathetic nervous system activation in healthy overweight males. British Journal of Clinical Pharmacology 201681 613-620. (https://doi.org/10.1111/bcp.12843)

47 Smits MM, Tonneijck L, Muskiet MHA, Hoekstra T, Kramer MHH, Diamant M \& van Raalte DH. Heart rate acceleration with GLP-1 receptor agonists in type 2 diabetes patients: an acute and 12-week randomised, double-blind, placebo-controlled trial. European Journal of Endocrinology 2017176 77-86. (https://doi.org/10.1530/EJE-160507)

48 Thazhath SS, Marathe CS, Wu T, Chang J, Khoo J, Kuo P, Checklin HL, Bound MJ, Rigda RS, Crouch B et al. The glucagonlike peptide-1 (GLP-1) receptor agonist, exenatide, inhibits small intestinal motility, flow, transit and absorption of glucose in healthy subjects and patients with type 2 diabetes: a randomised controlled trial. Diabetes 201665 269-275. (https://doi.org/10.2337/db150893)

Received 7 March 2019

Revised version received 26 May 2019

Accepted 3 June 2019 